\title{
Effects of a motilin receptor agonist (ABT-229) on upper gastrointestinal symptoms in type 1 diabetes mellitus: a randomised, double blind, placebo controlled trial
}

\author{
N J Talley, M Verlinden, D J Geenen, R B Hogan, D Riff, R W McCallum, R J Mack
}

\begin{abstract}
Introduction-Erythromycin, a motilin agonist, is a potent prokinetic. ABT-229 is a specific motilin agonist that dose dependently accelerates gastric emptying. Dyspepsia and gastroparesis are common problems in type 1 diabetes mellitus. We aimed to evaluate the efficacy of ABT-229 in symptomatic diabetic patients with and without delayed gastric emptying.

Methods-Patients with type 1 diabetes and postprandial symptoms were randomised $(n=270)$. Based on a validated $\mathbf{C}^{13}$ octanoic acid breath test, patients were assigned to either the delayed or normal gastric emptying strata. Patients received one of four doses of ABT-229 (1.25, 2.5, 5, or $10 \mathrm{mg}$ twice daily before breakfast and dinner) or placebo for four weeks following a two week baseline. A self report questionnaire measured symptoms on visual analogue scales; the primary outcome was assessment of change in the total upper abdominal symptom severity score (range $0-800 \mathrm{~mm}$ ) from baseline to the final visit.
\end{abstract}

Results-The treatment arms were similar regarding baseline characteristics. There was symptom improvement on placebo and a similar level of improvement on active therapy for the upper abdominal discomfort severity score (mean change from baseline $-169,-101,-155,-143$, and $-138 \mathrm{~mm}$ for placebo, and 1.25, 2.5, 5, and $10 \mathrm{mg}$ ABT-229, respectively, at four weeks by intent to treat). The results were not significantly different in those with and without delayed gastric emptying. The severity of bloating, postprandial nausea, epigastric discomfort, heartburn, and acid regurgitation worsened dose dependently in a greater number of patients receiving ABT-229 than placebo. Overall, $63 \%$ of patients on placebo reported a good or excellent global response, and this was not different from the active treatment arms.

Conclusions-The motilin agonist ABT229 was not efficacious in the relief of postprandial symptoms in diabetes mellitus in the presence or absence of delayed gastric emptying.

(Gut 2001;49:395-401)

Keywords: prokinetic; motilin; dyspepsia; gastric motility; type 1 diabetes; controlled trial; postprandial
Motilin is a 22 amino acid peptide hormone that is expressed throughout the gut. ${ }^{1}$ Motilin stimulates interdigestive antral contractions promoting gastric emptying; the receptor has recently been identified. ${ }^{2}$ Erythromycin is a potent motilin agonist, inducing phase 3 of the migrating motor complex ${ }^{1}$; it accelerates gastric emptying in healthy volunteers as well as in patients with diabetic gastroparesis or those post-vagotomy. ${ }^{34}$

Dyspepsia is a common problem in patients with diabetes mellitus. ${ }^{56}$ Between $27 \%$ and $58 \%$ of type 1 diabetics are reported to have gastroparesis, usually affecting solids but less often liquids. ${ }^{78}$ Symptoms of diabetic gastroparesis include postprandial distress, early satiety, bloating, fullness, and nausea and vomiting, but while gastroparesis is common, only a minority have overt symptomatology. ${ }^{78}$ Moreover, these symptoms also occur frequently in diabetics who do not have objective evidence of gastroparesis. ${ }^{6}$ The underlying mechanisms remain in dispute but disturbed vagal parasympathetic function and poor glycaemic control may both be important. ${ }^{89}$ In addition, increased levels of motilin have been observed in diabetic gastroparesis which is likely to be a compensatory mechanism as motilin levels decreased with the introduction of a prokinetic. ${ }^{10} \mathrm{~A}$ prokinetic agent in diabetic gastroparesis has the potential to increase gastric emptying, improve dyspepsia, and better control plasma glucose levels.

There has therefore been considerable interest in developing new prokinetics for gastroparesis, including motilin agonists that lack antibiotic activity. ABT-229 has potent motilin agonist activity with essentially no antibiotic action. ${ }^{11}{ }^{12}$ It dose dependently accelerates gastric emptying, and has a half life of 20 hours. ${ }^{11}{ }^{12}$ Multidose studies have shown that the maximally effective dose was $5 \mathrm{mg}$ twice daily for accelerating gastric emptying and 2.5 mg twice daily retained a modest but significant prokinetic effect. ${ }^{12}$

We aimed to test the hypothesis that ABT-229 would relieve postprandial symptoms in patients with diabetes mellitus. We further hypothesised that the maximum therapeutic gain over placebo would be observed in patients with diabetic gastroparesis on higher doses of ABT-229. To test these hypotheses, we conducted a randomised, placebo controlled,

Abbreviations used in this paper: $\mathrm{HbAl} \mathrm{c}$, glycated haemoglobin. 
dose ranging trial in North American patients with type 1 diabetes mellitus.

\section{Methods}

The trial was approved by the local institutional review boards, and all patients gave informed consent.

\section{PATIENT SELECTION}

Ambulatory patients at least 18 years of age with documented type 1 diabetes were eligible to be enrolled. All patients were by definition insulin dependent. A minimum three month history of chronic upper abdominal discomfort (that is, one or more of postprandial fullness, bloating, epigastric discomfort, early satiety, belching after meals, postprandial nausea, vomiting, or epigastric pain) was required. A total of 383 patients were screened (by 33 investigators in the USA and three in Canada between June 1997 and August 1998) (fig 1). Patients were required to have a normal upper endoscopy (that is, no ulcers or erosions in the oesophagus and gastroduodenum) in the three months before randomisation. Furthermore, during the baseline evaluation over 14 days, patients had to have experienced one or more symptoms of postprandial upper abdominal discomfort on three or more days per week and on average have sufficiently severe symptoms (defined as an upper abdominal discomfort severity score of $>149 \mathrm{~mm}$ and a postprandial fullness severity score of $>29 \mathrm{~mm}$ on visual analogue scales, as described below). Patients were only enrolled if there were no serious comorbid illnesses and screening laboratory values were normal.

Excluded were patients with gastrooesophageal reflux disease, based on a normal endoscopy (only erythema was permitted), and

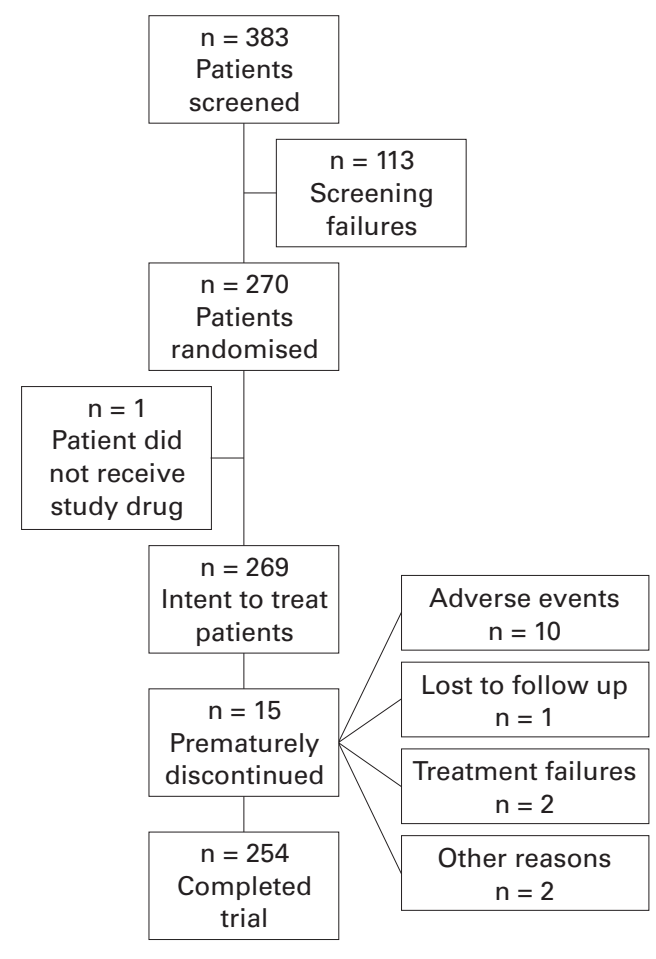

Figure 1 Patient flow chart. patients with predominant symptoms of irritable bowel syndrome. Use of prokinetic or antisecretory agents within 72 hours of the screening period or during the trial was not permitted. Occasional non-steroidal antiinflammatory drug use ( $<11$ days per month) or aspirin ( $<101 \mathrm{mg}$ daily) was allowed. A history of recent peptic ulceration (in the past five years if no Helicobacter pylori treatment had been received or one year if treated for $\mathrm{H}$ pylori) was an exclusion criterion. Patients with other serious diseases (including alcoholism and drug dependence, any bowel surgery, or malignancy) were excluded.

Overall, 113 patients were excluded on screening (20 ulcer or erosions, 11 other illnesses, eight other medications, 16 inadequate symptom level, two inadequate completion of the diary card, and the remainder miscellaneous other reasons).

\section{RANDOMISATION}

Each site was supplied with separate sets of study drug for the gastric emptying strata (normal and delayed); to ensure random assignment, patients in each strata were given a number in sequential order from a separate computer generated randomisation list.

A total of 270 patients were randomised but one was lost to follow up after the drug was dispensed and this patient was excluded. Patients treated $(n=269)$ were randomly assigned to receive ABT-229 $1.25 \mathrm{mg}(\mathrm{n}=55), 2.5$ $\mathrm{mg}(\mathrm{n}=58), 5 \mathrm{mg}(\mathrm{n}=53), 10 \mathrm{mg}(\mathrm{n}=55)$, or placebo $(n=48)$ twice daily before breakfast and dinner for four weeks. These four doses were chosen based on the gastrokinetic effects of ABT-229 administered in healthy subjects. ${ }^{12}$ The $2.5 \mathrm{mg}$ twice daily dose was only marginally significantly superior to placebo as it accelerated gastric emptying of the evening meal only. The maximally effective dose in healthy subjects was $5 \mathrm{mg}$ twice daily. As the gastrokinetic effects of ABT-229 were largest in those with slower gastric emptying, a $1.25 \mathrm{mg}$ dose was included in the trial. To account for the possibility that patients with diabetic gastroparesis might be more resistant to therapy and require a higher dose, $10 \mathrm{mg}$ was also included. Overall, 15 patients prematurely discontinued; the reasons were adverse events $(n=10)$, treatment failure $(n=2)$, lost to follow up $(n=1)$, or other reasons $(n=2)$, and the distribution was similar in each arm (fig 1). In total, 254 patients completed the trial.

\section{BLINDING}

The placebo was identical in appearance to active therapy. All medication was supplied in double blinded multidose bottles. An administrative blind break occurred for one patient.

\section{COMPLIANCE}

Compliance, measured by a tablet count at week 4, was excellent. A minimum of $97 \%$ of patients in each treatment arm were at least $75 \%$ compliant. 
ASSESSMENT OF GASTRIC EMPTYING

A standardised $\mathrm{C}^{13}$ octanoic acid breath test was used to stratify patients during screening. ${ }^{12-16}$ After fasting for 12 hours, patients consumed a $420 \mathrm{kcal}$ breakfast meal comprising $50 \mathrm{~g}$ of ham, one fried egg, $10 \mathrm{~g}$ of butter, two slices of white bread, $100 \mathrm{ml}$ of orange juice, and $100 \mathrm{ml}$ of water $(45 \%$ carbohydrates, $37 \%$ fat, and $18 \%$ protein), administered in an upright sitting position in $10 \mathrm{~min}$ utes. Breath samples were obtained 10 minutes before the meal and every 10 minutes for the first two hours, and then every 15 minutes for a further two hours. Breath samples were analysed at a central laboratory. In a healthy adult reference population in the USA $(n=50$, Abbott Laboratories, Abbott Park, Illinois, USA, data on file) using the same meal, the mean $t_{50}$ was 130 (50) minutes and the 90th percentile was 193 minutes; definite delayed gastric emptying in this trial was defined a priori as $>192$ minutes. Overall, $29 \%$ of patients had definite delayed gastric emptying by these criteria, which are conservative, and this was similar across treatment arms. The breath test has been validated in 19 insulin dependent diabetics against scintigraphy using the same meal; the correlation coefficient for $t_{50}$ was 0.73 $(\mathrm{p}<0.001)$ (Abbott Laboratories, data on file).

\section{OUTCOME ASSESSMENTS}

Patient symptom questionnaire

At baseline, and at two and four weeks, all patients completed a self report measure of the severity, frequency, duration, and impact of meal related symptoms over the prior two weeks. The eight target symptoms were postprandial fullness, early satiety, bloating, epigastric discomfort (an ache or discomfort after eating, poorly localised), epigastric pain (a sharp, easy to pinpoint pain after eating), postprandial nausea, belching after meals, and vomiting. Severity was scored for each symptom on a $100 \mathrm{~mm}$ visual analogue scale. The primary outcome was defined a priori as the sum of the severities of the eight symptoms, to create the total upper abdominal discomfort severity score (minimum 0, maximum 800 $\mathrm{mm}$ ). Defining each symptom in lay person terms standardised the questionnaire. A visual analogue scale is sensitive to change and is well accepted as a tool for evaluating dyspepsia. ${ }^{17}$

Measured also were symptom frequency (from none to every day) and impact (from not at all bothersome to extremely bothersome) on five graded Likert scales, as well as duration (from not at all to continuous or almost continuous) on a seven graded Likert scale.

\section{Patient diary}

Patients completed a daily diary during the run in baseline and treatment periods. The severity of postprandial fullness, bloating, epigastric discomfort, and postprandial nausea were recorded on seven graded Likert scales from absent to cannot be ignored, prompt advice sought. The diary card assessments had been previously validated. ${ }^{17}$
Global evaluation

At week 4, patients rated the efficacy of treatment as follows: excellent (complete or near complete resolution of symptoms), good (distinct improvement), moderate (some improvement), or poor (no change or deterioration).

\section{Glycaemic control and all other measures}

Before randomisation, a serum glucose level was measured $(\mathrm{mg} / \mathrm{dl})$ by a central laboratory after fasting for 12 hours. During therapy, patients were required to conduct daily home glucose monitoring before breakfast, lunch, dinner, and bedtime, using their own monitoring system, and record the data in their diary. Glycated haemoglobin (HbA1c) levels were also measured at baseline and at the end of treatment (normal range 4.3-5.8\%). A 12 lead ECG was performed at baseline and at the final visit.

STATISTICAL ANALYSES

Primary analyses were conducted on patients who received at least one dose of study medication, and who had a baseline and at least one follow up symptom assessment no more than five days after the last dose (intent to treat). All $\mathrm{p}$ values calculated were two tailed; the alpha level of significance was set at 0.05 .

Baseline comparability among treatment groups was assessed by one way ANOVA for continuous variables and by Fisher's generalised exact test for categorical variables.

For the upper abdominal discomfort score, the sum of symptom severity scores from the patient diary, and severity scores for individual symptoms, treatment differences at baseline and for change from baseline were assessed by two way ANOVA, with factors for treatment, investigator, and treatment by investigator interaction. A linear dose-response was tested within the framework of multiple regression.

Treatment differences in the percentage of patients with worsened severity for individual symptoms were assessed by a CochranMantel-Haenszel test with investigators as strata. Treatment differences for global efficacy variables were also assessed by the CochranMantel-Haenszel test with investigators as strata.

A sample size of 50 patients per treatment arm was calculated to provide more than $80 \%$ power (using a two sided 0.05 level of significance) to detect a standardised treatment difference of 0.56 (the expected treatment difference divided by the standard deviation). A standardised treatment difference of greater than 0.56 was observed in previous studies testing cisapride, ${ }^{18}$ and a larger difference was considered reasonable to expect with ABT-229 in the absence of better estimates.

\section{Results}

BASELINE CHARACTERISTICS BY TREATMENT ARM Baseline demographic characteristics, gastrointestinal symptoms, and history of diabetic complications were generally similar in each treatment arm (table 1). Mean age of the study population was 45 years; $66 \%$ were females 
Table 1 Baseline characteristics of the intent to treat study population

\begin{tabular}{|c|c|c|c|c|c|}
\hline Variable & $\begin{array}{l}\text { Placebo } \\
(n=46)\end{array}$ & $\begin{array}{l}A B T-2291.25 \mathrm{mg} \\
\text { bid }(n=52)\end{array}$ & $\begin{array}{l}\text { ABT-229 2.5 mg } \\
\text { bid }(n=57)\end{array}$ & $\begin{array}{l}\text { ABT-2295 mg } \\
\text { bid }(n=52)\end{array}$ & $\begin{array}{l}\text { ABT-229 } 10 \mathrm{mg} \\
\text { bid }(n=54)\end{array}$ \\
\hline Age (y) (mean (SD)) & $45.0(13.4)$ & $45.6(13.7)$ & $43.3(10.4)$ & $44.0(12.3)$ & $45.9(12.0)$ \\
\hline Age at first diagnosis of diabetes (y) (mean (SD)) & $23.4(13.5)$ & $24.3(14.5)$ & $21.5(12.0)$ & $21.8(14.2)$ & $23.6(13.6)$ \\
\hline Female $(\%)$ & 65 & 67 & 65 & 62 & 69 \\
\hline Body mass index (mean (SD)) & $27.0(4.9)$ & $26.3(5.2)$ & $26.0(5.9)$ & $27.4(6.2)$ & $28.7(7.3)$ \\
\hline Cisapride use previous 2 years $(\%)$ & 50 & 51 & 50 & 40 & 40 \\
\hline Good/excellent response to cisapride previous 2 years (5) & 25 & 22 & 24 & 34 & 14 \\
\hline Metoclopramide use previous 2 years (\%) & 25 & 20 & 28 & 26 & 20 \\
\hline Good/excellent response to metoclopramide previous 2 years (\%) & 17 & 0 & 25 & 21 & 0 \\
\hline Caucasian (\%) & 91 & 90 & 91 & 85 & 87 \\
\hline Peripheral neuropathy ${ }^{1}(\%)$ & 65 & 56 & 60 & 56 & 59 \\
\hline Autonomic neuropathy $^{1}(\%)$ & 17 & 8 & 23 & 29 & 6 \\
\hline Renal insufficiency ${ }^{1}(\%)$ & 17 & 12 & 7 & 10 & 6 \\
\hline Retinopathy ${ }^{1}(\%)$ & 48 & 37 & 49 & 46 & 39 \\
\hline Delayed gastric emptying (\%) & 23.9 & 28.8 & 31.6 & 28.8 & 31.5 \\
\hline Upper abdominal discomfort severity score (mm) (model based mean (SD)) & $387.8(130.5)$ & $378.4(133.4)$ & $375.9(136.5)$ & $362.3(125.5)$ & $376.3(135.6)$ \\
\hline Average sum of symptom severity score (diary) (mean SD)) & $8.7(3.4)$ & $8.1(3.8)$ & $7.8(4.4)$ & $8.1(3.8)$ & $8.4(3.8)$ \\
\hline
\end{tabular}

${ }^{1}$ Data based on investigator's statement that the condition was present and associated with diabetes.

and $89 \%$ were White. Mean height and weight were $169 \mathrm{~cm}$ and $77 \mathrm{~kg}$, respectively. Mean age at diagnosis of diabetes was 23 years, and mean number of years since diagnosis was 22 years. Overall, $22 \%$ were smokers. The majority of patients had a history of peripheral neuropathy (59\%) which was not different across the treatment arms but autonomic neuropathy differed among the treatment groups (table 1). The total upper abdominal symptom severity score was significantly higher in those with a history of one or more diabetic complications (mean score (SEM) 382 (10.2)) compared with those who had no complications (mean score 326 $(15.1) ; \mathrm{p}=0.005)$. The prokinetic agents cisapride, metoclopramide, and erythromycin had been used in the past two years by $46 \%$, $24 \%$, and $10 \%$, respectively, but use was reasonably similar across the treatment arms. A good or excellent response to previous use of

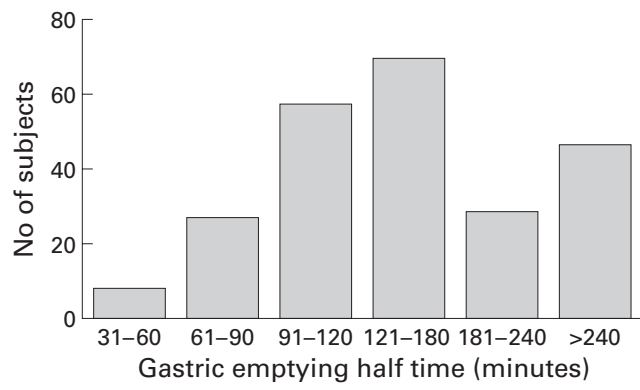

Figure 2 Distribution of gastric emptying half times $\left(t^{1 / 2}\right)$ in the study population.

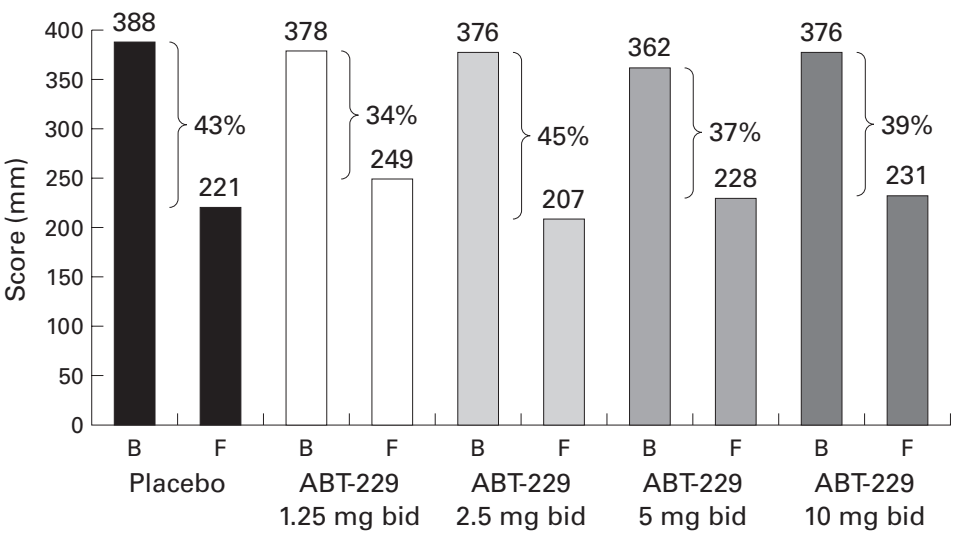

Figure 3 Mean upper abdominal discomfort score on combined visual analogue scales $(\mathrm{mm})$ at baseline $(B)$ and at the four week (final $(F)$ ) visit in each treatment arm. cisapride, metoclopramide, and erythromycin was reported by $23 \%, 16 \%$, and $22 \%$, respectively, and a moderate response by $48 \%$, $33 \%$, and $33 \%$, respectively. The distribution of half gastric emptying times in the total patient cohort is shown in fig 2 .

\section{PATIENT SYMPTOM QUESTIONNAIRE}

The total upper abdominal discomfort severity score, the primary outcome, decreased in all treatment arms from baseline, based on the intent to treat analysis (fig 3). There were no significant differences between each of the active treatment arms and placebo for mean change from baseline to week 2 or week 4 (table 2)

Improvement in the total upper abdominal symptom severity over baseline scores was $37 \%, 34 \%, 31 \%, 29 \%$, and $37 \%$ with placebo, and $1.25,2.5,5.0$, and $10.0 \mathrm{mg}$ of ABT-229, respectively, in patients with delayed gastric emptying. Patients with normal gastric emptying had even less improvement with the highest dose of ABT-229 (41\%, 29\%, 39\%, 39\%, and $22 \%$, respectively, for placebo, and $1.25,2.5$, 5.0, and $10.0 \mathrm{mg}$ of ABT-229) (table 2).

Almost identical results were observed applying a per protocol analysis. There was no treatment by investigator interaction, and there was no significant dose-response relationship including or excluding placebo.

When individual symptoms were analysed, ABT-229 was not superior to placebo; indeed, the severity of bloating, postprandial nausea, epigastric pain, heartburn, and acid regurgitation worsened dose dependently in a greater number of patients receiving ABT-229 than placebo (table 3).

PATIENT DIARY

Diary data suggested an inverse dose-response relationship for the severity of fullness, epigastric bloating, epigastric discomfort, and postprandial nausea; the sum of their scores decreased by $42 \%$ over baseline for placebo, and by $30 \%, 36 \%, 35 \%$, and $26 \%$ for $1.25,2.5$, 5.0 , and $10.0 \mathrm{mg}$ of ABT-229, respectively. There were no significant differences detected between placebo and any treatment group for the sum of the symptom severity scores, averaged over 14 day periods, except for $10 \mathrm{mg}$ of ABT-229 which was significantly worse than 
Table 2 Mean change in symptoms from baseline (intent to treat)

\begin{tabular}{|c|c|c|c|c|c|}
\hline $\begin{array}{l}\text { Mean (SEM) symptom score (mm) (model } \\
\text { based change from baseline to weeks 3-4) }\end{array}$ & Placebo bid & $\begin{array}{l}\text { ABT-229 } \\
1.25 \mathrm{mg} \text { bid }\end{array}$ & $\begin{array}{l}\text { ABT-229 } \\
2.5 \mathrm{mg} \text { bid }\end{array}$ & $\begin{array}{l}\text { ABT-229 } \\
5.0 \mathrm{mg} \text { bid }\end{array}$ & $\begin{array}{l}\text { ABT-229 } \\
10 \mathrm{mg} \text { bid }\end{array}$ \\
\hline \multicolumn{6}{|l|}{ Upper abdominal discomfort severity score } \\
\hline Normal gastric emptying & $-168(26)$ & $-114(26)$ & $-188(25)$ & $-143(26)$ & $-142(26)$ \\
\hline Delayed gastric emptying & $-163(47)$ & $-168(40)$ & $-129(37)$ & $-113(40)$ & $-153(38)$ \\
\hline Overall $^{\star}$ & $-169(25)$ & $-101(25)$ & $-155(24)$ & $-143(25)$ & $-138(26)$ \\
\hline \multicolumn{6}{|c|}{ Patient diary sum of symptom severity scores } \\
\hline Normal gastric emptying & $-3.8(0.7)$ & $-2.2(0.6)$ & $-3.1(0.6)$ & $-3.0(0.6)$ & $-1.9(0.6)$ \\
\hline Delayed gastric emptying & $-2.8(1.2)$ & $-3.0(1.0)$ & $-2.4(1.0)$ & $-2.3(1.0)$ & $-2.9(1.0)$ \\
\hline Overall & $-3.5(0.7)$ & $-1.8(0.7)$ & $-2.2(0.6)$ & $-2.9(0.7)$ & $-2.2(0.7)$ \\
\hline
\end{tabular}

^Adjusting for gastric emptying status.

Table 3 Change in symptom severity score two weeks after treatment initiation, measured by patient symptom questionnaire (visual analogue scale, VAS): \% of patients whose severity score changed

\begin{tabular}{|c|c|c|c|c|c|}
\hline & \multirow[b]{2}{*}{ Placebo } & \multicolumn{4}{|c|}{ ABT-229 (mg bid) } \\
\hline & & 1.25 & 2.5 & 5.0 & 10.0 \\
\hline \multicolumn{6}{|c|}{ Postprandial fullness } \\
\hline Worsened & 18 & 14 & 21 & 29 & 30 \\
\hline Improved & 82 & 82 & 79 & 67 & 67 \\
\hline \multicolumn{6}{|l|}{ Bloating } \\
\hline Worsened & 20 & $4^{\star}$ & 21 & 31 & $41^{\star}$ \\
\hline Improved & 77 & 88 & 75 & 67 & 57 \\
\hline \multicolumn{6}{|c|}{ Epigastric pain } \\
\hline Worsened & 25 & 24 & 23 & $33^{\star \star}$ & $46^{\star}$ \\
\hline Improved & 70 & 65 & 66 & 49 & 44 \\
\hline \multicolumn{6}{|c|}{ Postprandial nausea } \\
\hline Worsened & 18 & 24 & 21 & 25 & $35^{\star \star}$ \\
\hline Improved & 77 & 71 & 70 & 69 & 63 \\
\hline \multicolumn{6}{|c|}{ Daytime heartburn } \\
\hline Worsened & 16 & 25 & 28 & $33^{\star \star}$ & $31^{\star \star}$ \\
\hline Improved & 66 & 61 & 58 & 54 & 50 \\
\hline \multicolumn{6}{|c|}{ Night-time regurgitation } \\
\hline Worsened & 20 & 25 & 25 & $29 \star \star$ & $30^{\star \star}$ \\
\hline Improved & 66 & 55 & 45 & 42 & 43 \\
\hline
\end{tabular}

${ }^{\star} \mathrm{p} \leqslant 0.05,{ }^{\star \star} 0.05<\mathrm{p} \leqslant 0.1$ versus placebo.

placebo throughout the trial (fig 4). There was no significant interaction between investigator and treatment for mean change in baseline symptom scores to final evaluation. In the initial two week treatment period, epigastric discomfort severity scores were significantly worse for $10 \mathrm{mg}$ of ABT-229 than placebo $(\mathrm{p}<0.05)$. Similarly, the improvement in postprandial fullness tended to be significantly less in the $10 \mathrm{mg}$ ABT-229 arm than in the placebo group throughout the trial, and this difference was statistically significant in patients with normal gastric emptying $(\mathrm{p}<0.05)$.

GLOBAL EFFICACY

A similar percentage of patients on placebo reported a good to excellent response (63\%)

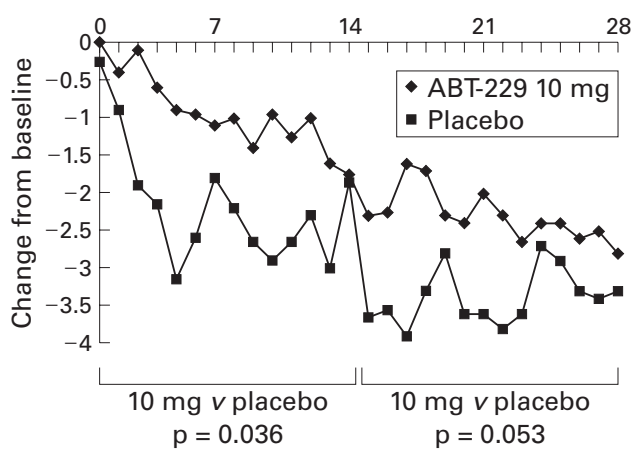

Figure 4 Change from baseline for the sum of daily severity scores for fullness, bloating, epigastric discomfort, and postprandial nausea from the patient diary in the placebo and ABT-229 $10 \mathrm{mg}$ groups. compared with the $1.25 \mathrm{mg}(54 \%), 2.5 \mathrm{mg}$ $(65 \%), 5 \mathrm{mg}(59 \%)$, and $10 \mathrm{mg}$ doses $(52 \%)$ of ABT-229.

GLYCAEMIC CONTROL, AUTONOMIC NEUROPATHY, AND OUTCOME

In secondary analyses, potential confounders were evaluated. Serum glucose levels and $\mathrm{HbA} 1 \mathrm{C}$ at baseline were strongly correlated (Spearman $r=0.42 ; \mathrm{p}<0.0001$ ). There was no significant correlation between baseline HbA1C and the baseline upper abdominal symptom score $(r=-0.09, \mathrm{p}=0.15)$. The upper abdominal discomfort score was weakly negatively correlated with baseline fasting serum glucose levels $(r=-0.17, \mathrm{p}=0.007)$. There was no evidence of correlation between change in upper abdominal symptom score when expressed as either absolute change or percentage change and corresponding changes in blood glucose or HbA1C (when expressed as either absolute change or percentage change) in the placebo $(-0.05 \leqslant r \leqslant 0.21$; all $\mathrm{p}>0.1), 1.25 \mathrm{mg}$ $(-0.23 \leqslant r \leqslant 0.15$; all $\mathrm{p}>0.1), 2.5 \mathrm{mg}(-0.05 \leqslant$ $r \leqslant 0.15$; all $\mathrm{p}>0.1), 5 \mathrm{mg}(-0.10 \leqslant r \leqslant 0.05$; all $\mathrm{p}>0.4)$, or the $10 \mathrm{mg}(0.03 \leqslant r \leqslant 0.15$; all $\mathrm{p}>0.3)$ treatment groups. There was no significant treatment difference between any ABT229 dose and placebo when stratifying for the presence or absence of autonomic neuropathy (defined as present or absent by the investigator).

SAFETY

All doses were well tolerated, and side effects were similar across the treatment arms. Headache, nausea, vomiting, abdominal pain, diarrhoea, infection, and hypoglycaemia were the most common adverse events. Study treatment was discontinued because of adverse events in only four patients on placebo and five on active treatment. The QT interval (normal defined as $<450 \mathrm{~ms}$ ) was not significantly prolonged from baseline in any of the treatment groups.

\section{Discussion}

Between $27 \%$ and $58 \%$ of type 1 diabetics have gastroparesis $^{7819-21}$ although the condition is not associated with a poorer prognosis. ${ }^{22}$ The risk of delayed gastric emptying is considered to be increased in those with type 1 diabetes of more than 10 years' duration who also have peripheral or autonomic neuropathy. ${ }^{7}$ Baseline symptoms correlate poorly with gastroparesis in diabetes but acceleration of gastric emptying is considered central to the management of dyspepsia in diabetes. ${ }^{23}$ In an open study of 24 patients with gastroparesis followed for two 
years, cisapride improved gastric emptying in 10 patients and seven showed a greater than $20 \%$ improvement in overall symptom score. ${ }^{24}$ However, only a minority had diabetic gastroparesis and no control group was evaluated. ${ }^{24}$ Other placebo controlled studies of prokinetics in type 1 diabetes however have been more disappointing. ${ }^{25}$

Erythromycin appears to be a more potent prokinetic than cisapride, domperidone, or metoclopramide. ${ }^{26}$ ABT-229 is similarly a potent promotility agent. ${ }^{127}$ The current trial results however suggest that ABT-229 does not relieve meal related upper gastrointestinal symptoms in type 1 diabetes mellitus. Indeed, the symptom outcomes were similar regardless of whether there was delayed or normal gastric emptying in this population. ABT-229 worsened the severity of fullness, bloating, epigastric discomfort, postprandial nausea, heartburn, and acid regurgitation in one third to a half of patients, and on average did so in twice as many patients compared with placebo. While the $1.25 \mathrm{mg}$ dose was significantly less detrimental for bloating than the other doses, this may represent a chance finding (because of multiple comparison testing). The data were consistent regardless of the outcome assessments applied, and adjustment for possible confounders did not alter the conclusions. We chose doses based on preliminary data clearly demonstrating a dose dependent acceleration of gastric emptying in healthy subjects. ${ }^{12}$ In these studies, twice daily dosing with $5 \mathrm{mg}$ of ABT-229 accelerated gastric emptying at breakfast, lunch, and dinner; three times daily dosing on $5 \mathrm{mg}$ or higher doses were not more effective. ${ }^{12}$ There is also no evidence that the effect of ABT-229 is subject to tachyphylaxis. ${ }^{12}$ Therefore, we do not consider it likely that incorrect doses were chosen for testing. While an evaluation of gastric emptying was not repeated on treatment, which is a limitation of the present study, a high enough dose was chosen to ensure a gastrokinetic effect. Moreover, in case this prokinetic drug was more potent in the diseased stomach than in health, a very low dose was also chosen.

Gastrointestinal symptoms in diabetes are usually attributed to disordered motor function, secondary to irreversible autonomic (vagal) neuropathy. ${ }^{7}$ However, symptoms tend to correlate poorly with the rate of gastrointestinal transit, ${ }^{28}$ and indeed in the present study only approximately one in four symptomatic patients had definite gastric emptying delay. The $\mathrm{C}^{13}$ octanoic acid breath test is considered less accurate than scintigraphy but the test does provide reasonably accurate intraindividual comparisons in diabetics, and is noninvasive. ${ }^{141528}$ There is evidence that blood glucose concentration can influence upper gut motor function and symptoms such as fullness and nausea. ${ }^{29}{ }^{30}$ We found no significant correlation between changes in symptom scores on treatment and changes in glycaemic control, as measured by HbA1C or recorded blood glucose levels on therapy. No association between symptom outcome and diabetic complications was observed although the baseline total upper abdominal symptom severity score was modestly higher in those with diabetic complications. However, data on diabetic complications (autonomic neuropathy, peripheral neuropathy, renal insufficiency, and retinopathy) relied on the judgement of the attending endocrinologist, and therefore the study may have underestimated the prevalence.

In a negative study, the possibility of a type II error needs to be considered. The present study was, we believe, adequately powered. Although few data are available to accurately estimate the likely therapeutic gain, the study was powered to detect a therapeutic gain similar or superior to that reported for cisapride in dyspepsia. Hence we cannot dismiss having missed a small effect but this is unlikely to be of clinical significance. The gastrokinetic effects of erythromycin may be less during hyperglycaemia than euglycaemia ${ }^{31}{ }^{32}$ and theoretically prokinetics may alter glycaemic control ${ }^{33}{ }^{34}$ but this was not observed in the present trial. Because even high doses of ABT-229 were not efficacious and we found no association between glycaemic control levels and treatment outcome, any such bias is unlikely to explain the negative results.

Mechanisms that may be relevant to the generation of dyspepsia in diabetes include slow gastric emptying, changes in antral or fundic tone associated with an abnormal meal distribution, and visceral hypersensitivity. ${ }^{35-37}$ It is conceivable that ABT-229 did not relieve dyspepsia in this study, despite probably increasing gastric emptying, primarily because it failed to enhance fundic relaxation. ${ }^{38}$ Failure of fundic relaxation appears to be an important mechanism in a subset of patients with functional dyspepsia, ${ }^{35}$ and may also be relevant in patients with diabetes who have vagal neuropathy but normal gastric sensation. ${ }^{39}$ Erythromycin has been shown to enhance fasting gastric tone at low dose but at high dose reduced the duration of meal induced relaxation. ${ }^{40}$ While similar data are not available for other specific motilin agonists, it is likely they also impair fundic relaxation; indeed, ABT-229 was not efficacious in functional dyspepsia in a recent large randomised controlled trial. ${ }^{41}$

In conclusion, in patients with type 1 diabetes and postprandial distress, the prokinetic ABT-229 failed to provide symptomatic relief compared with placebo. At the highest gastrokinetic dose of $10 \mathrm{mg}$ twice daily, ABT-229 appeared to worsen the severity of most symptoms in up to half of the patients. The results suggest that prokinetic therapy with the new specific motilin agonist drug class will not be of value in diabetic dyspepsia.

This study was sponsored by Abbott Laboratories, Abbott Park (Illinois, USA). The assistance of Patricia Wozniak with the statistical analyses is gratefully acknowledged. The following investigators contributed patients to this trial: N Chiba MD, Raleigh, Ontario, Canada; B A Connor MD, New York, USA; M D Dalton MD, Fort Worth, Texas, USA; J M Dorf MD, FCCP, Chicago, Illinois, USA; A Dubois MD, PhD, Bethesda, Maryland USA. R N Fediak Maryland, USA; R N Fedoriak MD, FRCP (C), FACP, Alberta,
Canada; R S Fisher MD, Philadelphia, Pennsylvania, USA; Canada; R S Fisher MD, Philadelphia, Pennsylvania, USA; R Gilbert MD, Boston, Massachusetts, USA; J M Gordon MD, Cleveland, Ohio, USA; R Hardi MD, PC, Chevy Chase, Maryland, USA; J Johanson MD, Rockford, Illinois, USA; D G Kogut $\mathrm{MD}$, Statesville, North Carolina, USA; D G Mangels, MD,
Cincinnati, Ohio, USA; J R Mathias MD, Houston, Texas, USA; 
P B Miner Jr MD, Oklahoma City, Oklahoma, USA; P Molloy MD, Pittsburgh, Pennsylvania, USA; J S Morgan MD, Asheville, North Carolina, USA; J Muchmore MD, Oklahoma City, Oklahoma, USA; B Overholt MD, Knoxville, Tennessee,
USA; P Poitras MD, Quebec, Canada; E B Portnoy MD, WestUSA; P Poitras MD, Quebec, Canada; E B Portnoy MD, Westlake Village, California, USA; C Schmitt MD, Chattanooga, Tennessee, USA; H I Schwartz MD, Miami, Florida, USA; S
Schwartz MD, San Antonia, Texas, USA; L J Siegel MD, San Schwartz MD, San Antonia, Texas, USA; L J Siegel MD, San Antonio, Texas, USA; W Snape MD, Long Beach, California, USA; C A Sninsky MD, Gainesville, Florida, USA; E E Soffer MD, Cleveland, Ohio, USA; R Summers MD, Iowa City, Iowa, CC, Ontario, Canada; A Wald MD, Pittsburgh, Pennsylvania, USA.

Conflict of interest: $\mathrm{N}$ Talley received a research grant from Abbott.

1 Peeters TL. Erythromycin and other macrolides as prokinetic agents. Gastroenterology 1993;105:1886-99.

2 Feighnner SD, Tan CP, McKee KK, et al. Receptor for motilin identified in the human gastrointestinal system. Science 1999;284:2184-8.

3 Kendall BJ, Chakravarti A, Kendall E, et al. The effect of intravenous erythromycin on solid meal gastric emptying in intravenous erythromycin on solid meal gastric emptying in patients with chronic symptomatic post-vagotomoyantrecto $381-5$.

4 Annese V, Lombardi G, Frusciante V, et al. Cisapride and erythromycin prokinetic effects in gastroparesis due to type 1 (insulin-dependent) diabetes mellitus. Aliment Pharmaco Ther 1997;11:599-603.

5 Feldman M, Schiller LR. Disorders of gastrointestinal motility associated with diabetes mellitus. Ann Intern Med 1983;98:378-84.

6 Bytzer PM, Hammer J, Talley NJ, et al. Gastrointestinal symptoms in diabetes mellitus are associated with diabetic complications but not with current glycemic control. Gastroenterology 2000;118:A468.

7 Horowitz M, Edelbroek M, Fraser R, et al. Disordered gastric motor function in diabetes mellitus. Recent insights into prevalence, pathophysiology, clinical relevance, and treatment. Scand $\mathcal{f}$ Gastroenterol 1991;26:673-84.

8 Malagelada JR. Diabetic gastroparesis. Semin Gastrointest Dis 1995;6:181-6.

9 MacGregor IL, Gueller R, Watts HD, et al. The effect of acute hyperglycemia on gastric emptying in man. Gastroenacute hyperglycemia on
terology $1976 ; 70: 190-6$.

10 Achem-Karam SR, Funakoshi A, Vinik AI, et al. Plasma motilin concentration and interdigestive misrating motor complex in diabetic gastroparesis: effect of metoclopramide. Gastroenterology 1985;88:492-9.

11 Verhagen MA, Samsom M, Maes B, et al. Effects of a new motilide, ABT-229, on gastric emptying and postprandial antroduodenal motility in healthy volunteers. Aliment Pharmacol Ther 1997;11:1077-86.

12 Verlinden M, Craft C, Olson C, et al. Abbott-812290, a new macrolide agent, dose-dependently accelerates solid gastric emptying (GE) in health volunteers. Gastroenterology 1997 112:A846.

13 Ghoos YF, Maes BD, Geypens BJ, et al. Measurement of gastric emptying rate of solids by means of a carbonlabelled octanoic acid breath test. Gastroenterology 1993; 104:1640-7.

14 Choi MG, Camilleri M, Burton DD, et al. ${ }^{13} \mathrm{C}$ octanoic acid breath test for gastric emptying of solids: accuracy, reproducibility, and comparison with scintigraphy. Gastroenterology $1997 \cdot 112 \cdot 1155-62$.

15 Lee JS, Camilleri M, Zinsmeister A, et al. Accurate, simple measurement of gastric emptying by ${ }^{13} \mathrm{C}$ octanoic acid breath test (OBT) in diabetics. Gastroenterology 1999;116 G4207.

16 Galmiche JP, Belbende B, Perri F, et al. ${ }^{13} \mathrm{C}$ octanoic acid breath test. Gut 1998;43(suppl 3):S28-30.

17 Nyren O, Adami HO, Bates S, et al. Self-rating of pain in nonulcer dyspepsia: A methodological study comparing a new fixed point scale and the visual analog scale. 7 Clin Gastroenterol 1987;9:408-14.

18 Finney JS, Kinnersley N, Hughes M, et al. Meta-analysis of antisecretory and gastrokinetic compounds in functional dyspepsia. F Clin Gastroenterol 1998;26:312-20.

19 Keshavarizian A, Iber FL, Vaeth J. Gastric emptying in patients with insulin-requiring diabetes mellitus. Am $\mathcal{F}$ Gastroenterol 1987;89:29.
20 Lyrenas EB, Olsson EH, Arvidsson UC, et al. Prevalence and determinants of solid and liquid gastric emptying in unstable type I diabetes. Relationship to post prandial blood glucose concentrations. Diabetes Care 1997;20:413.

21 Ewing DJ, Clare BF. Diagnosis and management of diabetic autonomic neuropathy. BMF 1982;285:916-18.

22 Kong MF, Horowitz M, Jones KL, et al. Natural history of diabetic gastroparesis. Diabetes Care 1999;22:503-7.

23 Patterson D, Abell T, Rothstein R, et al. A double-blind mulitcenter comparison of domperidone and metoclopramide in the treatment of diabetic patients with symptoms of gastroparesis. Am f Gastroenterol 1999;94:1230-4.

24 Kendall BJ, Kendall ET, Soykan I, et al. Cisapride in the long-term treatment of chronic gastroparesis: a 2-year open-label study. F Int Med Res 1997;25:182-9.

25 Stacher G, Schernthaner G, Francesconi M, et al. Cisparide versus placebo for 8 weeks on glycemic control and gastric emptying in insulin-dependent diabetes: A double blind cross-over trial. F Clin Endocrinol Metab 1999;84:2357-62.

26 Sturm A, Holtmann G, Goebell H, et al. Prokinetics in patients with gastroparesis: a systematic analysis. Digestion 1999;60:422-7.

27 Clarke MJ, Wright T, Bertrand PP, et al. Erythromycin derivatives ABT229 and GM611 act on motilin receptors in the rabbit duodenum. Clin Exp Pharmacol Physiol 1999; 26:242-5.

28 Ziegler D, Schadewaldt P, Pour Mirza A, et al. ${ }^{13} \mathrm{C}$ octanoic acid breath test for non-invasive assessment of gastric emptying in diabetic patients: validation and relationship to gastric symptoms and cardiovascular autonomic function. Diabetologia 1996;39:823-30.

29 Kong MF, Horowitz M. Gastric emptying in diabetes mellitus: relationship to blood-glucose control. Clin Geriatr Med 1999;15:321-38.

30 Rayner CK, Verhagen MA, Hebbard GS, et al. Proximal gastric compliance and perception of distension in type 1 diabetes mellitus: effects of hyperglycemia. Am $\mathcal{F}$ Gastroenterol 2000; 95:1175-83.

31 Petrakis IE, Vrachassotakis N, Sciacca V, et al. Hyperglycaemia attenuates erythromycin-induced acceleration of solidphase gastric emptying in idiopathic and diabetic gastroparesis. Scand f Gastroenterol 1999;34:396-403.

32 Jones KL, Berry $\mathrm{M}$, Kong MF, et al. Hyperglycemia attentuates the gastrokinetic effect of erythromycin and affects the perception of postprandial hunger in normal subjects. Diabetes Care 1999;22:339-44.

33 Ishii M, Nakamura T, Kasai F, et al. Erythromycin derivative improves gastric emptying and insulin requirement in diabetic patients with gastroparesis. Diabetes Care 1997;20:1134-7.

34 Ueno N, Inui A, Asakawa A, et al. Erythromycin improves glycaemic control in patients with type II diabetes mellitus. Diabetologia 2000;43:411-15.

35 Undeland KA, Hausken T, Svebak S, et al. Wide gastric antrum and low vagal tone in patients with diabetes mellitus type I compared to patients with functional dyspepsia and healthy individuals. Dig Dis Sci 1996;41:9-16.

36 Undeland KA, Hausken T, Gilja OH, et al. Gastric meal accommodation studied by ultrasound in diabetes. Relation to vagal tone. Scand $\mathcal{F}$ Gastroenterol 1998;33:236-41.

37 Hebbard GS, Samsom M, Sue WM, et al. Hyperglycemia affects proximal gastric motor and sensory function during small intestinal triglyceride infusion. Am f Physiol 1996; 271:G814-19.

38 Tack J, Piessevaux H, Coulie B, et al. Role of impaired gastric accommodation to a meal in functional dyspepsia. Gastroenterology 1998;115:1346-52.

39 Troncon L, Rosa E, Silva L, et al. Abnormal intragastric distribution of a liquid nutrient meal in patients with diabetes mellitis. Dig Dis Sci 1998;43:1421-9.

40 Bruley des Varannes S, Parys V, Ropert A, et al. Erythromycin enhances fasting and postprandial proximal gastric tone in humans. Gastroenterology 1995;109:32-9.

41 Talley NJ, Verlinden M, Snape W, et al. Failure of a motilin receptor agonist (ABT-229) to relieve the symptoms of trolled trial. Aliment Pharmacol Ther 2000;14:1653-61. 